\title{
Evaluating the Effect of Gesture and Language on Personality Perception in Conversational Agents
}

\author{
Michael Neff ${ }^{1}$, Yingying Wang ${ }^{1}$, Rob Abbott ${ }^{2}$, and Marilyn Walker ${ }^{2}$ \\ 1 University of California, Davis \\ \{mpneff|yiwang\}@ucdavis.edu \\ 2 University of California, Santa Cruz \\ $\{$ abbott|maw $\}$ @soe.ucsc.edu
}

\begin{abstract}
A significant goal in multi-modal virtual agent research is to determine how to vary expressive qualities of a character so that it is perceived in a desired way. The "Big Five" model of personality offers a potential framework for organizing these expressive variations. In this work, we focus on one parameter in this model - extraversion - and demonstrate how both verbal and non-verbal factors impact its perception. Relevant findings from the psychology literature are summarized. Based on these, an experiment was conducted with a virtual agent that demonstrates how language generation, gesture rate and a set of movement performance parameters can be varied to increase or decrease the perceived extraversion. Each of these factors was shown to be significant. These results offer guidance to agent designers on how best to create specific characters.
\end{abstract}

Keywords: personality, gesture, conversational and non-verbal behavior, evaluation

\section{Introduction}

An important focus of recent research on interactive story systems, computer gaming, and educational virtual worlds is the development of animated Intelligent Virtual Agents (IVAs) $[12,18,11,28,36,13]$. For such characters to be effective they must simulate the most effective human interlocutors: they must be natural and believable, but moreover, they must convey personality, mood, and expression $[1,32,21,37,23]$. Determining how to represent such affective and individual qualities in a computational framework remains an active research problem. Gestures, speech, and facial behaviors must be precisely coordinated and their performance must be procedurally controlled to express a realistic and consistent character that responds to the current context. One possible theoretical foundation for producing such behaviors is the the "Big Five" model of personality traits. In this paper we focus on the Big Five trait of extraversion. We examine whether an agent whose verbal and nonverbal behavior is controlled 
using parameters suggested by previous research on extraversion is perceived by naive users as projecting the personality that our system intends.

Over the last fifty years the Big Five theory has become a standard in psychology. Research has systematically documented correlations between a wide range of behaviors and the Big Five traits (extraversion, neuroticism, agreeableness, conscientiousness, openness to experience) [24, 29,31]. For example, research has shown that verbal behaviors are influenced by personality. Extraverts talk more, faster, louder, and more repetitively than introverts, using fewer pauses and hesitations, and with a lower type/token ratio [8]. Extraverts are less formal and use more positive emotion words and more references to context [14,31]. Spatial nonverbal attributes such as body attitude, gesture amplitude or expansiveness, motion direction, motion smoothness and fluency have also been shown to be key indicators of personality, as well as temporal attributes like gesture speed and response latency. Just as extraverts tend to have high speech rate and produce more utterances, they also have high gesture rates $[2,30,20,25]$.

Section 2 summarizes the findings from psychology on the expression of extraversion, including a novel synthesis of research on non-verbal factors, and explains how we use these to derive parameters for both verbal and nonverbal IVA behavior. The main contribution of this paper is a study described in Section 3 , that shows how verbal and non-verbal factors can be combined to affect user perceptions of levels of extraversion of an IVA, as shown in the results in Section 4 . We show that all of our parameters have a significant effect on the perception of extraversion and provide an indication of how they combine. We delay a detailed description of related work to the conclusion (Section 5) where we can directly compare our approach to previous work on the generation of gesture.

\section{Nonverbal and Verbal Expression of Personality}

Table 1: Trait adjectives associated with the extremes of the Extraversion trait.

\begin{tabular}{|l|l|l|}
\hline & High & Low \\
\hline Extraversion & $\begin{array}{l}\text { warm, gregarious, assertive, so- } \\
\text { ciable, excitement seeking, ac- quiet, reserved, passive, } \\
\text { tive, spontaneous, optimistic, } \\
\text { talkative }\end{array}$ & solitary, moody, joyless \\
\hline
\end{tabular}

In previous work $[22,21]$, we argue that the Big Five model of personality provides a useful framework for modeling some types of stylistic linguistic variation. Here we focus on the Big Five trait of extraversion, whose corresponding trait adjectives are shown in Table 1 . We believe that these trait adjectives provide an intuitive, meaningful definition of linguistic style [7, 29]. Below we review 
the psychology literature on the expression of extraversion and explain how we derive IVA parameters from this previous work.

\subsection{Nonverbal Expression of Extraversion}

One of the primary contributions of this paper is to review and organize findings from psychology on the nonverbal expression of the extraversion personality trait. Our summary of these findings is shown in Table 2. Postural and gestural styles are linked to personality, attitude and status in relationships $[25,15]$.

The position of the head and trunk are the most visually salient indicators of status and attitude; leaning forward communicates a relatively positive attitude to the interlocutor whereas leaning backward or turning away communicates a more negative attitude. Leaning the torso forward is also positively correlated with extraversion [20]. Frank [6] similarly argues that extraverts amplify a sense of space by moving the upper body (chest and limbs) forward whereas introverts maintain a more vertical orientation.

Table 2: The gestural correlates of extraversion.

\begin{tabular}{|l|l|l|}
\hline & Introversion & Extraversion \\
\hline Body attitude & backward leaning, turning away & forward leaning \\
\hline Gesture amplitude & narrow & wide, broad \\
\hline $\begin{array}{l}\text { Gesture direction } \\
\text { Gesture rate }\end{array}$ & loward, self-contact & $\begin{array}{l}\text { outward, table-plane and horizon- } \\
\text { tal spreading gesture }\end{array}$ \\
\hline $\begin{array}{l}\text { Gesture speed, re- } \\
\text { sponse time } \\
\text { mesture connection more mements of head, hands } \\
\text { and legs }\end{array}$ \\
\hline Body part & $\begin{array}{l}\text { flow smoothness, rhythm distur- } \\
\text { bance }\end{array}$ & $\begin{array}{l}\text { smooth, fluent } \\
\text { head tilt, shoulder erect, chest for- } \\
\text { ward, limbs spread, elbows away } \\
\text { from body, hands away from body, } \\
\text { legs apart, legs leaning, bouncing, } \\
\text { shaking of legs }\end{array}$ \\
\hline
\end{tabular}

Several studies have shown that gestural expansiveness and range of movement is positively correlated with extraversion $[2,3]$. Specifically extraversion is positively correlated to factors like "expansive", "broad gestures", "elbows away from body", "hands away from body", and "legs far apart while standing" [20, $33,17]$.

Gesture direction is also important. Argyle [2] states that introverts use fewer outward directed gestures and touch themselves more. North [30] indicates that extraverts likely show a significant number of table plane and horizontal spreading gestures. The analysis of tests by Takala [35] demonstrate the hypothesis that introverts use more inward directed movements in the horizontal dimension and extraverts more outward directed movements. Furthermore, movements directed away from the person could be an indication of aggressiveness, while inward directed shifts indicate passiveness. 
Extraverts are found to be more energetic or have more physical strength, and higher gesture rates, while the gestures of introverts persist more $[20,3,17$, $9,2]$. A number of studies have examined the temporal properties of gestures [17, 33]. Extraverts tend to have faster speech, which leads to higher gesture rates due to the correlation between speech and gesture. This has been experimentally demonstrated by Lippa [20]. Brebner [3] also found differences between introverts and extraverts in speed and frequency of movement. Extraverts not only behave in a more rapid manner than introverts, the time to first response, or the response latency, is shorter as well. Results related to the smoothness and rhythm of gesture suggest that introversion is negatively correlated with smoothness and positively correlated with rhythm disturbance [33, 20,35].

Other research discusses extraversion and its relation to particular body parts in gesturing. Knapp [17] mentions more leg lean for an ambitious personality. Experiments by Riggio [33] suggest extraverts have more "body emphasis", defined as more head movements, more parallel gestures of the hands, more movement of the legs(position, bouncing, shaking) and more posture shifts. Besides using broad gestures, Lippa [20] also found that extraverts use most of their body when gesturing, tend to tilt their heads and raise their shoulders. Extraverts are universally believed to maintain more eye contact, and a positive correlation between eye contact, shoulder orientation, leg orientation, and body orientation indicates extraversion [25].

In addition, it is postulated that spatial behavior also differs for extraverts [2, 30]. For example, it has been hypothesized that extraverts stand closer to others, either because of greater tolerance for a close interaction distance, or because of high individual confidence, self-esteem, or assertiveness.

Gesture Parameters Two dimensions of motion variation were developed based on the findings discussed above. The first is gesture rate which can be either "high" or "low". The high rate used approximately twice as many gestures as the low for a given utterance. The second, termed gesture performance, includes a range of changes to posture, gesture form and timing. It has four evenly spaced levels ranging from "most extraverted" to "least extraverted".

Gesture performance consists of the following factors. For each, the most and least extraverted parameter values are listed in Table 3 (the row label in the table is in bold in the text below). For increased extraversion, the spatial scale of the gesture stroke was increased and it was moved up and out to the side of the character (stroke scale and stroke position). The duration was shortened. The combined duration change and spatial scaling effectively increase the velocity of the stroke. In terms of posture, for high extraversion, the elbows were rotated out (arm swivel), the shoulders were raised (collar bones) and a forward lean was added through a shift of the center of mass forward and a forward rotation at the base of the spine (spine rotation forward and COM shift forward). For the more introverted examples, the amount of body movement was scaled down both in the torso and the lower body (body motion scale). This included bringing the feet closer together to narrow the stance. 
Table 3: Gesture Parameter Settings.

\begin{tabular}{|l|l|l|}
\hline parameter & max introversion & max extraversion \\
\hline \hline stroke scale & $\mathrm{x}^{*} .5, \mathrm{y}^{*} \cdot 6, \mathrm{z}^{*} .8$ & $\mathrm{x} * 1.4, \mathrm{y}^{*} 1.2, \mathrm{z}^{*} 1.1$ \\
\hline stroke position & $\mathrm{x}-12 \mathrm{~cm}, \mathrm{y}-5 \mathrm{~cm}$ & $\mathrm{x}+12 \mathrm{~cm}, \mathrm{y}+10 \mathrm{~cm}$ \\
\hline duration & $100 \%$ & $80 \%$ \\
\hline collar bones & down $5 \mathrm{deg}$ & up 10 deg. \\
\hline arm swivel & $\begin{array}{l}33 \text { degree range between ex- } \\
\text { tremes }\end{array}$ \\
\hline spine rotation forward & $-6 \mathrm{deg}$ & $6 \mathrm{deg}$ \\
\hline COM shift forward & $-5 \mathrm{~cm}$ & $6 \mathrm{~cm}$ \\
\hline Body motion scale & $\begin{array}{l}\text { varies between } 10 \text { and } 60 \% \text { de- } \\
\text { pending on parameter }\end{array}$ & 100\% \\
\hline
\end{tabular}

\subsection{Verbal Expression of Extraversion}

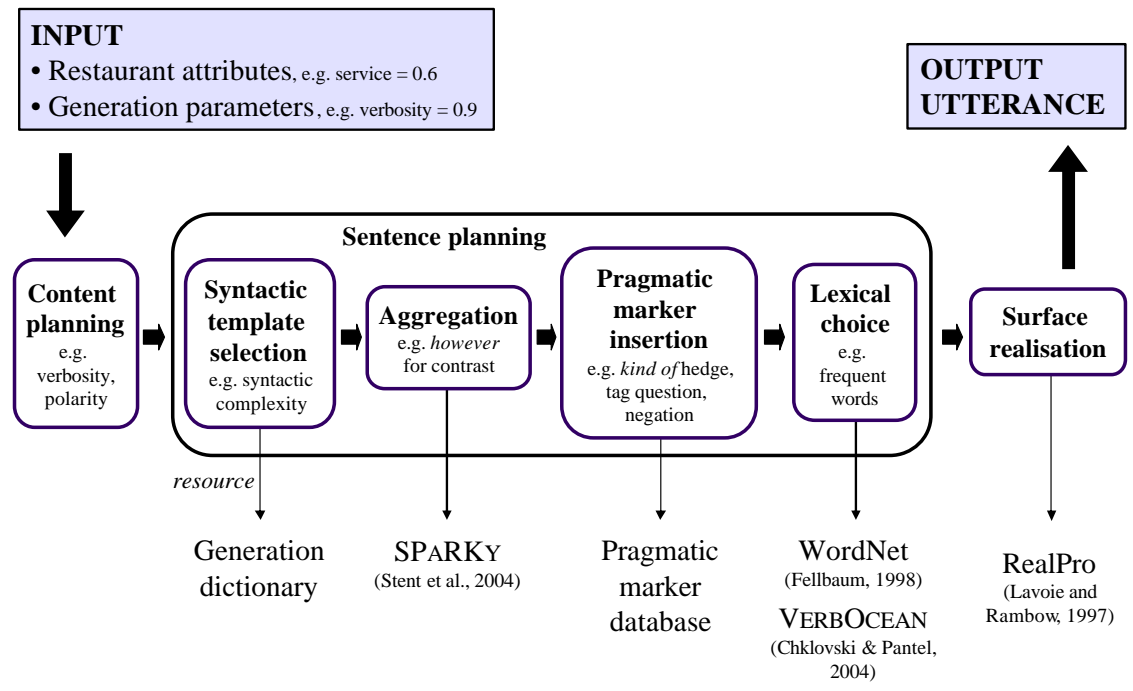

Fig. 1: The architecture of the PERSONAGE generator.

Our experiments use the PeRsonage generator for verbal realization of extraversion. The Personage architecture is shown in Figure 1. Table 4 provides a detailed description of many of the linguistic parameters relevant to the expression of extraversion ${ }^{3}$ In Personage, generation parameters are implemented, and their values are set, based on correlations between linguistic cues and the

${ }^{3}$ Personage provides additional parameters for expressing extraversion as well as parameters for other traits. 
Big Five traits that have been systematically documented in the psychology literature $[31,24,34,8]$. For example, parameters for the extraversion trait include VERBOSITY, SYNTACTIC COMPLEXITY, and CONTENT POLARITY, which controls the production of positive content. See Table 4 . The right-most columns contain the parameter values for expressing either introversion or extraversion. Parameter values are specified in terms of low and high settings, and then mapped to normalized scalar values between 0 and 1 . More detail about how the PERSONAGE parameters were derived from the psychology literature can be found in [22, $21]$.

Table 4: Sample of some PERSONAGE parameters used to express extraversion.

\begin{tabular}{|c|c|c|c|}
\hline Parameter & Description & Intro & Extra \\
\hline VERBOSITY & Control the number of propositions in the utterance & low & high \\
\hline RESTATEMENTS & $\begin{array}{l}\text { Paraphrase an existing proposition, e.g. 'Chanpen Thai has } \\
\text { great service, it has fantastic waiters' }\end{array}$ & low & high \\
\hline CONTENT POLARITY & $\begin{array}{l}\text { Control the polarity of the propositions expressed, i.e. re- } \\
\text { ferring to negative or positive attributes }\end{array}$ & low & high \\
\hline CONCESSION POLARITY & $\begin{array}{l}\text { Determine whether positive or negative attributes are em- } \\
\text { phasized }\end{array}$ & low & high \\
\hline POSITIVE CONTENT FIRST & $\begin{array}{l}\text { Determine whether positive propositions-including the } \\
\text { claim-are uttered first }\end{array}$ & low & high \\
\hline REQUEST CONFIRMATION & $\begin{array}{l}\text { Begin the utterance with a confirmation of the restaurant's } \\
\text { name, e.g. 'did you say Chanpen Thai?' }\end{array}$ & low & high \\
\hline SYNTACTIC COMPLEXITY & Control the syntactic complexity (syntactic embedding) & high & low \\
\hline TEMPLATE POLARITY & $\begin{array}{l}\text { Control the connotation of the claim, i.e. whether positive } \\
\text { or negative affect is expressed }\end{array}$ & low & high \\
\hline Although Cue Word & $\begin{array}{l}\text { Concede a proposition using although, e.g. 'Although Chan- } \\
\text { pen Thai has great service, it has bad decor' }\end{array}$ & high & low \\
\hline Negation & $\begin{array}{l}\text { Negate a verb by replacing its modifier by its antonym, e.g. } \\
\text { 'Chanpen Thai doesn't have bad service' }\end{array}$ & high & low \\
\hline SOFTENER HEDGES & $\begin{array}{l}\text { Insert syntactic elements (sort of, kind of, somewhat, quite, } \\
\text { around, rather, I think that, it seems that, it seems to me } \\
\text { that) to mitigate the strength of a proposition, e.g. 'It seems } \\
\text { to me that Chanpen Thai has rather great service' }\end{array}$ & high & low \\
\hline ACKNOWLEDGMENTS: & $\begin{array}{l}\text { Insert an initial back-channel (yeah, right, ok, I see, oh, } \\
\text { well), e.g. 'Well, Chanpen Thai has great service' }\end{array}$ & low & high \\
\hline NEAR EXPLEtives & Insert a near-swear word, e.g. 'the service is darn great' & low & high \\
\hline Filled pauses & $\begin{array}{l}\text { Insert syntactic elements expressing hesitancy (like, I mean, } \\
\text { err, mmhm, you know), e.g. 'I mean, Chanpen Thai has } \\
\text { great service, you know' or 'Err... Chanpen Thai has, like, } \\
\text { great service, }\end{array}$ & high & low \\
\hline EMPHASIZER HEDGES & $\begin{array}{l}\text { Insert syntactic elements (really, basically, actually, just) to } \\
\text { strengthen a proposition, e.g. 'Chanpen Thai has really } \\
\text { great service' or 'Basically, Chanpen Thai just has great } \\
\text { service' }\end{array}$ & low & high \\
\hline EXCLAMATION & $\begin{array}{l}\text { Insert an exclamation mark, e.g. 'Chanpen Thai has great } \\
\text { service!' }\end{array}$ & low & high \\
\hline TAG QUESTION & Insert a tag question, e.g. 'the service is great, isn't it?' & low & high \\
\hline IN-GROUP MARKER & $\begin{array}{l}\text { Refer to the hearer as a member of the same social group, } \\
\text { e.g. pal and buddy }\end{array}$ & low & high \\
\hline LEXICON FREQUENCY & Control the average frequency of use of each content word & low & high \\
\hline VERB STRENGTH & $\begin{array}{l}\text { Control the strength of the verbs, e.g. suggest vs. recom- } \\
\text { mend }\end{array}$ & low & high \\
\hline
\end{tabular}




\section{Experimental Design}

Our main hypotheses are that verbal and nonverbal cues to personality will reinforce each other when they are congruent and that when verbal and nonverbal cues are mixed, the perceptual effect is graded. In order to test this, we combine verbal cues in the form of restaurant recommendations generated by PERSONAGE with nonverbal cues in the form of gestures generated by animation software based on $[26,28]$ and rendered using the EMBR agent [13].

Four restaurant recommendations, shown below, that were generated by PERSONAGE were selected for use in the experiment, with audio generated using the VoiceText from Voiceware with the "Kate" voice:

- low extraversion 1: I mean, Amy's Bread isn't as bad as the others.

- low extraversion 2: It seems that Orange Hut is the only restaurant with friendly staff that is any good.

- high extraversion 1: I am sure you would like Amy's Bread. Basically, its price is 12 dollars, its cheap, you know, the food is good and the servers are friendly.

- high extraversion 2: I am sure you would like Orange Hut, you know. Basically, the food is great and the atmosphere is good with friendly service.

Gestures were aligned with words in the input utterances based on the information structure of each utterance in terms of theme and rheme [4]. The low gesture rate examples used about half of the placement locations of the high gesture rate examples. For both of the low extraversion utterances, the low rate sample has one gesture and the high rate sample has two. For the high extraversion examples, one had a high rate of five gestures and a low rate of three and the other a high rate of four and low rate of two.

Animated clips were generated using a combination of motion capture editing and procedural synthesis using algorithms based on our previous work [28, 26]. Motion capture data of the wrist positions was used to specify the path of the wrist in each stroke and inverse kinematics was used to complete the arm motion. The stroke phases of six sample gestures were chosen for the experiment that all had similar form (a slight upward arc, like the shape of a frown) and an initial distance between start and end points of approximately $25 \mathrm{~cm}$. These included left, right and two handed gestures. The final gesture lengths would be scaled based on the performance parameters.

Each gesture consisted of preparation, stroke and retraction phases. The preparation and retraction phases were procedurally generated and started or ended (respectively) at the side of the character's waist. If there was not enough time to complete a retraction, a preparation would be inserted that joined the end of one gesture to the beginning of the next. For each utterance, a set of gestures was chosen based on the duration of each matched word and ensuring that a given gesture sample was not repeated. These gestures were then used in all examples for that utterance. For the low rate examples, some of the gestures were simply dropped from the sequence generation. A single piece of torso and 
lower body motion capture data was used to animate the body in every clip. The animation data was rendered using the EMBR agent.

Every combination of rate and gesture performance was generated for each of the four utterances, yielding 32 total clips $(2 \times 4 \times 4)$ for use in the experiment. The head was blocked out by a gray square in the videos to encourage subjects to attune to the character's body movement. See Figure 2. A video showing labeled example clips used in the experiment is available online ${ }^{4}$.

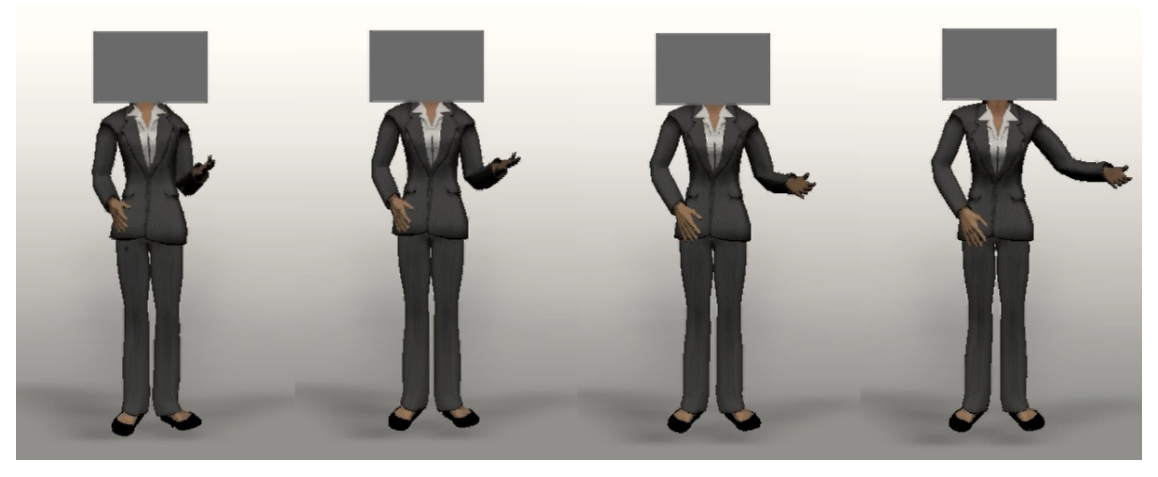

Fig. 2: Gesture performance extraversion styles in order of increasing extraversion

\subsection{Experiment Execution}

We recruited 40 subjects for a web-based experiment. The majority of subjects were undergraduate university students. Eight were female and 32 were male. Thirty four were between 18 and 30 years of age, three were between 31 and 50, and three were over 50. For five subjects English was not their first language. Prior to taking the survey, subjects were shown four sample clips and an overview of the questions to give them a sense of the scope of the experiment.

Subjects were presented a video of a female avatar making a restaurant recommendation and asked to judge her extraversion level and naturalness. The subjects were allowed to replay the video as many times as they wished but were not allowed to return to previous videos. The stimuli appeared in a random order for each subject. There were 32 videos and three 7 -point Likert scale questions per video. The 32 stimuli consisted of every combination of gesture rate (High, Low), gesture extraversion level (1-4), and utterance (1-4). The experiment took, on average, approximately 30 minutes to complete.

The subjects rated each stimulus utterance for perceived extraversion by answering the relevant questions measuring that trait from the Ten-Item Personality Inventory, as this instrument was shown to be psychometrically superior to a "single item per trait" questionnaire [10]. Specifically, the subject was asked

\footnotetext{
${ }^{4}$ http://www.cs.ucdavis.edu/ ${ }^{\sim}$ neff
} 
to rate the clips in a form that said "I see the speaker as...", and then had questions "1. Extroverted, enthusiastic" (Disagree Strongly/Agree Strongly) and "2. Reserved, quiet" (Disagree Strongly/ Agree Strongly). The second answer is inverted and the two are then averaged to produce a rating ranging from 1 (i.e. highly introvert) to 7 (i.e. highly extravert). Because it was unclear whether users would perceive the synthetic utterances as natural, the subjects also evaluated the naturalness of each utterance on the same scale. Our hypotheses were:

- H1: Combined gestural and linguistic manifestations of extraversion will be perceived as manifesting an equal combination of the extraversion of each input mode.

- H2: Higher gesture rates will be perceived as more extraverted.

- H3: The edited changes in gesture performance (Table 3) will correlate with perceived changes in extraversion.

- H4: Combining a higher gesture rate with a more "extraverted" performance will lead to a stronger perception of extraversion than either change on its own.

- H5: Perceived naturalness will be the same as PERSONAGE utterances presented textually, i.e. 5.3 average on a 7 point scale [21].

\section{Results}

All three experimental factors described above (language extraversion, gesture rate, and gesture performance) showed a positive correlation with perceived extraversion. A one-way ANOVA of performance extraversion on TIPI-extraversion is significant $(\mathrm{p}=.015, \mathrm{~F}=3.5, \mathrm{df}=3)$ confirming Hypothesis 3. See Fig. 3. A one-way ANOVA of language extraversion on TIPI-extraversion is significant ( $\mathrm{p}$ $<.001, \mathrm{~F}=55.5, \mathrm{df}=1$ ). See Fig. $5(\mathrm{a})$. A one-way ANOVA of gesture rate on TIPI-extraversion is significant $(\mathrm{p}<.001, \mathrm{~F}=17.1, \mathrm{df}=1)$ confirming Hypothesis 2. See Fig. 4. These results corroborate the findings in the literature (Sec. 2) on perceived markers of extraversion.

A multivariate linear regression of gesture rate, gesture performance and linguistic extraversion on TIPI extraversion shows that all of the parameters have a significant effect on the perception of extraversion.

$$
.09^{*} \text { Performance }+.12^{*} \text { Rate }+.21 * \text { LinguisticExtraversion }
$$

The standardized regression equation, shown above, accounts for $27 \%$ of the variance. Linguistic extraversion has the largest effect, disconfirming Hypothesis 1 , which posited that all modes would contribute equally. However the regression shows that all modes contribute to perception together, and as such confirms Hypothesis 4.

A one-way ANOVA examining the effect of performance extraversion and gesture rate on naturalness showed no significant effect. However linguistic extraversion affects naturalness, with extraverted utterances perceived as significantly less natural $(\mathrm{F}=15.08, \mathrm{df}=1, \mathrm{p}<.001)$. Thus Hypothesis 5 is disconfirmed. See Figure 5(b). In previous work we showed that the average naturalness 


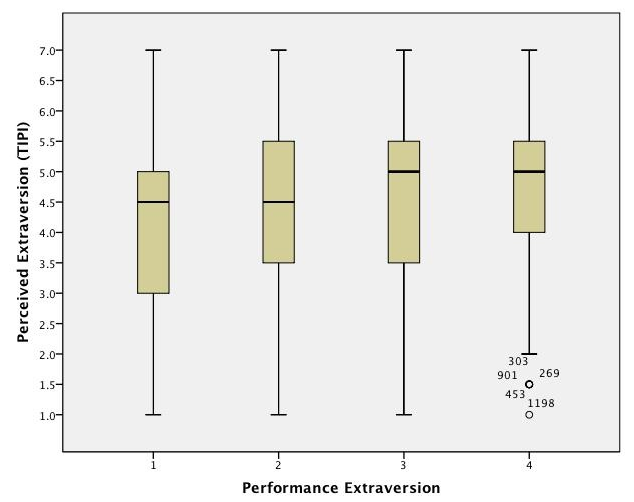

Fig. 3: Effect of Performance Extraversion on Perceived Extraversion (TIPI)

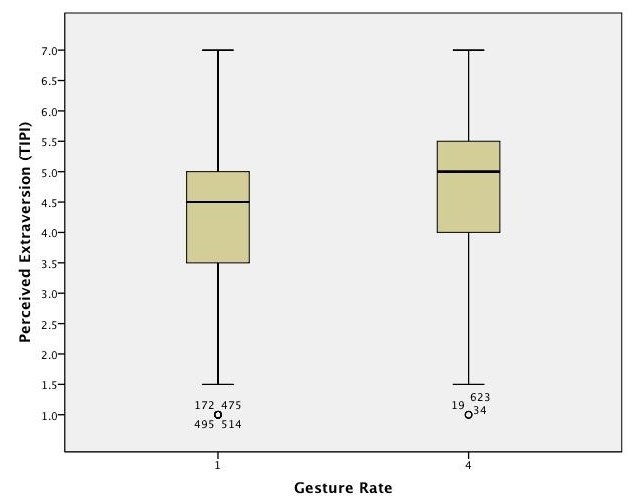

Fig. 4: Effect of Gesture Rate on Perceived Extraversion (TIPI)

of our extraversion utterances when presented as text was 5.78. Thus we posit two possibilities for the perceived unnaturalness of the highly extraverted utterances. First, it may reflect the fact that the text-to-speech engine is more likely to encounter a bad pronunciation or a bad join on a longer utterance, and our previous work used only text, rather than voice. The other possibility is that the perceived unnaturalness reflects the difficulties with developing a good algorithm for gesture placement on longer utterances. Previous work on gesture placement using theme and rheme has mainly focused on shorter utterances. Our extraverted utterances realize a claim and three satellites describing restaurant attributes, and are 25 words on average.

\section{Discussion and Conclusion}

This paper reports the results of an experiment analyzing the expression of extraversion using both verbal and nonverbal indicators. Our work aims to con- 


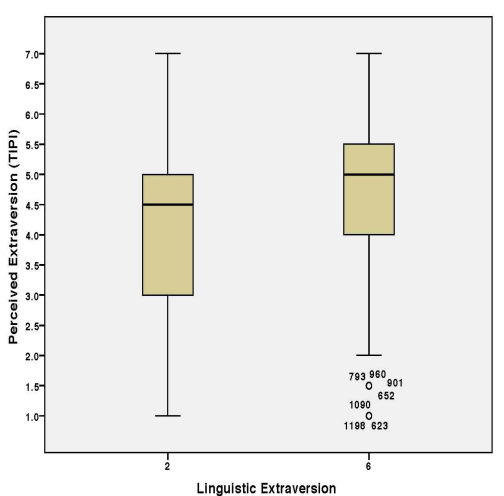

(a) Linguistic Extraversion on TIPI (b) Linguistic Extraversion on NatuExtraversion

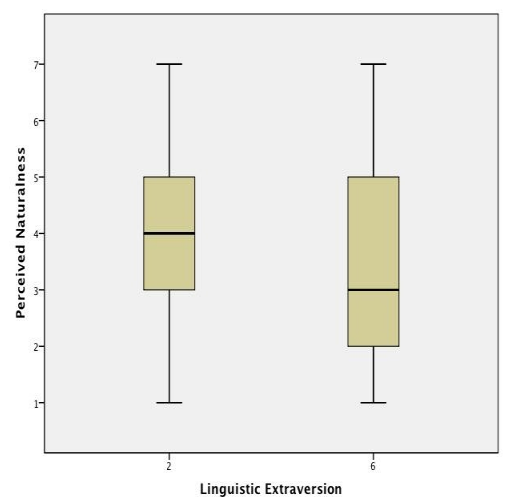

ralness

Fig. 5: The effect of Linguistic Extraversion TIPI Extraversion and Naturalness

tribute to a broader discourse on how to control the expressivity of animated agents.

Considerable previous work has focused on expressive procedural animation. For instance, Chi et al. [5] developed a model for arm and torso movement based on the Effort and Shape components of Laban Movement Analysis. Hartmann et al. [12] developed a gesture model with parameters for overall activation, spatial extent, temporal extent, fluidity, power and repetition. Neff and Fiume [27] present a system that allows a character sketch to be applied to a motion sequence to control its general form. These systems provide a movement palette, but do not indicate how to change these parameters to create a specific personality. It is our goal to establish mappings between movement parameters and perceived changes in personality.

Other research has examined how to align gestures with spoken utterances. For example Cassell et al. [4] present a system that suggests gesture placement based on linguistic structure. Kipp et al. [16] and Neff et al. [28] present a system that uses probabilistic rules to model the gesturing style of particular individuals in terms of both gesture placement and gesture form. Levine et al. [19] present a system that uses the prosody of spoken text to generate gestures. Our work does not directly contribute to gesture placement strategies, but establishes a relationship between gesture frequency and personality, while also indicating which movement variations are likely to be perceived as extraverted.

Other work has examined how particular aspects of movement are perceived by users. For instance, Kipp et al. [16] demonstrated that gesture units consisting of multiple gestures performed better than singleton gestures on a variety of criteria such as naturalness and friendliness, but found no result for extraversion. Isbister \& Nass [15] present the only other work we are aware of that examines the combination of gesture and linguistic expression of personality. They used 
fixed postures on an artist's model to accompany utterances hand scripted to convey either extraversion or introversion. This study used body expansiveness to indicate computer character's extraversion. Extraverted postures were designed with limbs spread wide from the body while introverted postures were designed with limbs close to the body. We move beyond this to full, multi-modal stimuli, including variations in both text generation and a wide range of movement parameters.

Our experiment demonstrates that each of the factors we tested - language variation, gesture rate, and a large set of gesture performance parameters - have a statistically significant impact on the perception of extraversion. Moreover, they continue to affect user perceptions of extraversion in multi-modal communication with a virtual agent and we can procedurally generate an agent that embodies these traits. The relative contribution of each of these factors was analyzed. We were surprised that misaligned combinations of parameters were perceived as just as natural as aligned combinations. There was no strong correlation between perceived naturalness and TIPI-Extraversion, though there was a correlation between our verbal extraversion parameters and naturalness.

This work indicates several potentially profitable avenues for further exploration. While a large set of movement parameters was used, other factors such as the direction of movement, smoothness and character relationships in dialogs were not explored and warrant further study. Establishing the relative contribution of each movement factor would also be worthwhile. Finally, the concept of naturalness is worth further elaboration, especially in the context of multi-modal stimuli where it can be difficult to ascertain what is dominating user judgments of naturalness (TTS quality, movement, text, or a combination of the factors).

\section{Acknowledgements}

Financial support for this research was provided in part by NSF grants 0832202 and 0845529 to UCD and in part by NSF grant 1002921 to UCSC. Thanks to Alexis Heloir for his support with EMBR, the subject participants for their time, and the anonymous reviewers for their useful comments.

\section{References}

1. André, E., Rist, T., van Mulken, S., Klesen, M., Baldes, S.: The automated design of believable dialogues for animated presentation teams. Embodied conversational agents pp. 220-255 (2000)

2. Argyle, M.: Bodily communication. Taylor \& Francis (1988)

3. Brebner, J.: Personality theory and movement. Individual differences in movement pp. 27-41 (1985)

4. Cassell, J., Vilhjálmsson, H., Bickmore, T.: BEAT: the Behavior Expression Animation Toolkit. In: Proceedings of SIGGRAPH 2001. pp. 477-486 (2001)

5. Chi, D.M., Costa, M., Zhao, L., Badler, N.I.: The EMOTE model for effort and shape. In: Proc. SIGGRAPH 2000. pp. 173-182 (2000) 
6. Frank, K.: Posture \& Perception in the Context of the Tonic Function Model of Structural Integration: an Introduction. IASI Yearbook 2007 pp. 27-35 (2007)

7. Funder, D.C.: The Personality Puzzle. W. W. Norton \& Company, New York, 2nd edn. (1997)

8. Furnham, A.: Language and personality. In: Giles, H., Robinson, W. (eds.) Handbook of Language and Social Psychology. Winley (1990)

9. Giles, H., Street, R.: Communicator characteristics and behavior. Handbook of interpersonal communication 2, 103-161 (1994)

10. Gosling, S.D., Rentfrow, P.J., Swann, W.B.: A very brief measure of the big five personality domains. Journal of Research in Personality 37, 504-528 (2003)

11. Hartmann, B., Mancini, M., Pelachaud, C.: Formational parameters and adaptive prototype installation for MPEG-4 compliant gesture synthesis. In: Proc. Computer Animation 2002. pp. 111-119 (2002)

12. Hartmann, B., Mancini, M., Pelachaud, C.: Implementing expressive gesture synthesis for embodied conversational agents. In: Proc. Gesture Workshop 2005. LNAI, vol. 3881, pp. 45-55. Springer, Berlin; Heidelberg (2006)

13. Heloir, A., Kipp, M.: EMBR-A Realtime Animation Engine for Interactive Embodied Agents. In: Intelligent Virtual Agents 09. pp. 393-404. Springer (2009)

14. Heylighen, F., Dewaele, J.M.: Variation in the contextuality of language: an empirical measure. Context in Context, Special issue of Foundations of Science 7(3), 293-340 (2002)

15. Isbister, K., Nass, C.: Consistency of personality in interactive characters: Verbal cues, non-verbal cues, and user characteristics. International Journal of Human Computer Studies 53(2), 251-268 (2000)

16. Kipp, M., Neff, M., Kipp, K., Albrecht, I.: Towards natural gesture synthesis: Evaluating gesture units in a data-driven approach to gesture synthesis. In: Proceedings of Intelligent Virtual Agents (IVA07). LNAI, vol. 4722, pp. 15-28. Association for Computational Linguistics (2007)

17. Knapp, M., Hall, J.: Nonverbal communication in human interaction. Holt, Rinehart and Winston New York (1978)

18. Kopp, S., Wachsmuth, I.: Synthesizing multimodal utterances for conversational agents. Computer Animation and Virtual Worlds 15, 39-52 (2004)

19. Levine, S., Theobalt, C., Koltun, V.: Real-time prosody-driven synthesis of body language. ACM Transactions on Graphics (TOG) 28(5), 1-10 (2009)

20. Lippa, R.: The nonverbal display and judgment of extraversion, masculinity, femininity, and gender diagnosticity: A lens model analysis. Journal of Research in Personality 32(1), 80-107 (1998)

21. Mairesse, F., Walker, M.A.: PERSONAGE: Personality generation for dialogue. In: Proceedings of the 45th Annual Meeting of the Association for Computational Linguistics (ACL). pp. 496-503 (2007)

22. Mairesse, F., Walker, M.A.: Trainable generation of Big-Five personality styles through data-driven parameter estimation. In: Proceedings of the 46th Annual Meeting of the Association for Computational Linguistics (ACL) (2008)

23. McQuiggan, S., Mott, B., Lester, J.: Modeling self-efficacy in intelligent tutoring systems: An inductive approach. User Modeling and User-Adapted Interaction 18(1), 81-123 (2008)

24. Mehl, M.R., Gosling, S.D., Pennebaker, J.W.: Personality in its natural habitat: Manifestations and implicit folk theories of personality in daily life. Journal of Personality and Social Psychology 90, 862-877 (2006)

25. Mehrabian, A.: Significance of posture and position in the communication of attitude and status relationships. Psychological Bulletin 71(5), 359-372 (1969) 
26. Neff, M., Kim, Y.: Interactive editing of motion style using drives and correlations. In: Proceedings of the 2009 ACM SIGGRAPH/Eurographics Symposium on Computer Animation. pp. 103-112. ACM (2009)

27. Neff, M., Fiume, E.: AER: Aesthetic Exploration and Refinement for expressive character animation. In: Proc. ACM SIGGRAPH / Eurographics Symposium on Computer Animation 2005. pp. 161-170 (2005)

28. Neff, M., Kipp, M., Albrecht, I., Seidel, H.P.: Gesture modeling and animation based on a probabilistic re-creation of speaker style. ACM Transactions on Graphics 27(1), 5:1-5:24 (Mar 2008)

29. Norman, W.T.: Toward an adequate taxonomy of personality attributes: Replicated factor structure in peer nomination personality rating. Journal of Abnormal and Social Psychology 66, 574-583 (1963)

30. North, M.: Personality assessment through movement. Macdonald and Evans (1972)

31. Pennebaker, J.W., King, L.A.: Linguistic styles: Language use as an individual difference. Journal of Personality and Social Psychology 77, 1296-1312 (1999)

32. Piwek, P.: A flexible pragmatics-driven language generator for animated agents. In: Proceedings of Annual Meeting of the European Chapter of the Association for Computational Linguistics (EACL) (2003)

33. Riggio, R., Friedman, H.: Impression formation: The role of expressive behavior. Journal of Personality and Social Psychology 50(2), 421-427 (1986)

34. Scherer, K.R.: Personality markers in speech. In: Scherer, K.R., Giles, H. (eds.) Social markers in speech, pp. 147-209. Cambridge University Press (1979)

35. Takala, M.: Studies of psychomotor personality tests, 1-. Suomalainen Tiedeakatemia (1953)

36. Thiebaux, M., Marshall, A., Marsella, S., Kallman, M.: Smartbody: Behavior realization for embodied conversational agents. In: Proc. of 7th Int. Conf. on Autonomous Agents and Multiagent Systems (AAMAS 2008). pp. 151-158 (2008)

37. Wang, N., Johnson, W.L., Mayer, R.E., Rizzo, P., Shaw, E., Collins, H.: The politeness effect: Pedagogical agents and learning gains. Frontiers in Artificial Intelligence and Applications 125, 686-693 (2005) 